Cantarero Tomás, David.

Artista Visual. Máster Oficial en Producción Artística, Universitat Politècnica de València.

\title{
Inquietar el ver. La metaimagen como herramienta crítica dentro de la investigación en Artes Visuales.
}

\author{
TIPO DE TRABAJO \\ Comunicación. \\ PALABRAS CLAVE \\ Metaimagen, hipericono, inconsciente óptico, imagen dialéctica, imagen pensativa.
}

KEY WORDS

Metaimage, hypericon, optical unconscious, dialectical image, thoughtful image.

\section{RESUMEN}

El siguiente proyecto de investigación contempla a la imagen en tanto que material con el que trabajar de forma crítica dentro de la producción en artes visuales, así como herramienta para la reflexión teórica. El término clave para articular esa doble dimensión teórico-práctica ha sido el de "metaimagen" -es decir, una reflexión visual de segundo grado sobre aquello que las propias imágenes son-, tal y como viene formulado en las ideas de W. J. T. Mitchell. Este concepto ha permitido dialectizar las dimensiones textual y visual de la investigación de tal manera que las diferentes obras producidas englobables bajo el mismo y materializadas en diferentes formatos como la fotografía, el video o la instalación audiovisual-, han "dado imagen a la teoría" -en la terminología de este mismo autor-condensando y visibilizando las ideas de diferentes referentes teóricos. Así, se han ido hilando, en diálogo con las piezas, las aportaciones de varios de los autores que con más relevancia se han ocupado recientemente de la producción de imágenes, en base a nociones como las de "inconsciente óptico" (J. L. Brea), "retórica de la ocultación" (M. Á. Hernández-Navarro), "realidad integral" (J. Baudrillard) o "imagen dialéctica" (G. Didi-Huberman) entre otras. Todo ello con el propósito de esclarecer si es viable hoy la tarea crítica de inquietar el ver, de trastocar la mirada, de un modo que nos permita resituarnos ante esa marea ingente de imágenes que nos rodea todos los días, frente a las cuales a menudo ponemos en marcha los mismos mecanismos perceptivointerpretativos. Averiguar si es posible convertir esta experiencia en espacio de reflexión, para poder repensar la relación existente entre las imágenes y el contexto del que fueron extraídas y en el que son mostradas, así como las cuestiones políticas, éticas y estéticas que vehiculan en cada momento y lugar.

\section{ABSTRACT}

The following research project considers the image as a material to work with critically into production in visual arts as well as a tool for theoretical thinking. The key term to articulate this double theoretical and practical dimension has been "metaimage" -that is, a second degree visual reflection on what the images themselves are-, as is formulated in the ideas of W. J. T. Mitchell. That concept has allowed to dialectize the textual and visual dimensions of the research so that the different artworks produced -includible under it and materialized in several formats like photography, video or audiovisual installation- have "given image to theory" -in the terminology of this same author-condensing and visualizing the ideas of different theoretical referents. So, they have been spinning in dialog with the pieces, the contributions of several of the most important authors that have recently dealt with the production of images, based on notions such as "optical unconscious" (J. Brea), "rhetoric of the occultation" (M. Á. Hernández-Navarro), "integral reality" (J. Baudrillard) or the "dialectical image" (G. Didi-Huberman) among others. All with the purpose of clarifying whether it is feasible today the critical task of disrupting seeing, of upsetting the gaze, in a way that allows to relocate us in front of this huge tide of images that surrounds us every day, against which we often run the same perceptive-interpretative mechanisms. To find out if it is possible turning this experience into a space for reflection, in order to rethink the current relation between images and the context from which they were extracted and in which they are displayed, as well as the political, ethical and aesthetical questions they carry at every time and place. 


\section{INTRODUCCIÓN}

Es éste un trabajo que discurre por una brecha, una falla o una sutura. Un recorrido de ida y vuelta, reenvíos, conexiones y fracturas entre el decir y el mostrar, entre el mirar y el narrar, entre el hacer ver por medio de la palabra, y la toma de consciencia por medio de la imagen. En él se analizarán varias nociones que pretenden problematizar la relación entre las imágenes, los discursos, la realidad, lo que muestran y cómo se muestran.

Atendiendo a esa articulación imagen/texto, se puede extraer el primero de los objetivos de la investigación, ${ }^{1}$ que es de corte metodológico: sería el de mostrar cómo la mencionada línea de investigación artística recoge, canaliza y visibiliza algunas de las ideas recientes más significativas sobre el arte contemporáneo y la cultura visual, posibilitando la elaboración de un discurso que conecta algunos de los autores que más notablemente se han ocupado de estas áreas en los últimos tiempos. Se hará uso a lo largo de todo el texto de diversas obras de producción propia que ayuden a visualizar, a "dar imagen" a la disertación teórica.

El segundo objetivo sería intentar que la parte teórica ayude a su vez a plantear una tesis de carácter teórico-práctico, una que se valide o reformule a la vez que la obra se introduce en el campo de lo experimental. Esta trataría de responder a la pregunta de si es posible hoy inquietar la mirada, "mostrar el ver", y en ese proceso extrañarlo de sí, hacia sí, con el fin de poder repensar cuestiones referentes a las relaciones de poder, dominación y hegemonía vinculadas a la visibilidad (y la invisibilidad) de las imágenes. Se pretende con esto elaborar un discurso híbrido, textual-visual, que cumpla su hipótesis en su propio despliegue espacio-temporal, en el que ese trabajo de inquietar la mirada incumba a las dos partes involucradas, la cuestión de indagación teórica y la investigación como producción artística.

\section{METAIMAGEN E HIPERICONO}

Este primer apartado trata la cuestión de la metodología y el modo en que se van a articular esos dos órdenes diferentes de representación, el visual y el textual. En Teoría de la imagen W.J.T. Mitchell aborda de manera detallada tanto esta problemática como el desarrollo de algunos de los conceptos de los que se hará uso más adelante. En primer lugar, este autor sostiene que la interacción entre imágenes y textos es constitutiva de la representación en sí, de manera que "todos los medios son mixtos y todas las representaciones son heterogéneas; no existen las artes «puramente» visuales o verbales, aunque el impulso de purificar los medios sea uno de los gestos utópicos más importantes del modernismo". ${ }^{2}$ Desde esta perspectiva el lugar en el que condensan todas las problemáticas en torno a la representación y su despliegue a través de las diferentes esferas del hacer humano, sería por lo tanto el espacio intermedio o lugar de divergencia, el límite o la fractura, entre la imagen y el texto, entre lo visual y lo verbal. Partiendo de este punto, para afrontar la tarea de analizar las diferentes modalidades de interrelación que pueden darse, establece una nueva figura compuesta que le permite desmarcarse de las aproximaciones teóricas que a lo largo de la historia han tratado de explicar, definir, acotar y controlar las imágenes, de manera que su estudio "examina la relación entre las imágenes y el discurso y trata de reemplazar una teoría, fundamentalmente binaria, sobre esa relación, con una imagen dialéctica, la figura de la «imagentexto»" ( $p$. 17). Si se la contempla de este modo, no se puede considerar la imagen/texto a la manera de "un concepto, sino como una figura teórica, parecida a la différance de Derrida, la sede de una tensión dialéctica, de un deslizamiento y una transformación" (p. 98).

Dentro de la relación imagen-texto, Mitchell cataloga o delimita un tipo específico de imágenes que denomina "metaimágenes". ${ }^{3}$ Éstas, tal y como las describe el autor, son en primer lugar "imágenes que se refieren a otras imágenes, imágenes que se utilizan para mostrar qué es una imagen" (p. 39), de tal manera que "miran a las imágenes «en tanto que» teoría, como reflexiones de segundo orden sobre las prácticas de representación visual; se preguntan qué es lo que las imágenes nos dicen cuando se teorizan (o se representan) a sí mismas" (p. 17), al tiempo que "revelan la inextricable imbricación de la representación y el discurso, la forma en que la experiencia visual y verbal están entretejidas" (p.79).

Pero según afirma Mitchell el factor "visual" no sería el único que entra en juego, dado que "la autorreferencia de la imagen no es una característica exclusivamente formal e interna que distinga a unas imágenes de otras, sino un elemento funcional y pragmático, una cuestión de uso y contexto" (p. 57). Lo que propone entonces es que las metaimágenes pueden tomar la forma de un "hipericono",

\footnotetext{
${ }^{1}$ El presente texto forma parte del trabajo de investigación que actualmente estoy desarrollando dentro del Máster Oficial en Producción Artística de la Universitat Politècnica de València. Los avances que aquí figuran formarán por lo tanto parte del Trabajo Final de Máster. En él será donde se analicen con mayor detenimiento las nociones que aquí aparecerán meramente esbozadas, y donde se profundice en las posibles afinidades, conexiones y oposiciones que se puedan dar entre los diferentes planteamientos.

${ }^{2}$ W. J. T. Mitchell, Teoría de la imagen. Ensayos sobre representación verbal y visual, Madrid, Akal, 2009, p. 12. Se puede seguir un análisis más completo de este asunto a lo largo del texto, en específico en las páginas 88-91. Asimismo, le dedica un detenido análisis en el capítulo "No existen medios visuales" en Brea, J., Estudios Visuales. La epistemología de la visualidad en la era de la globalización, Madrid, Akal, 2005, pp. 17-25.

${ }^{3}$ El autor establece una primera catalogación meramente aproximativa dependiendo del aspecto en el que inciden, pudiendo tratarse de cuestiones perceptivas, cuestiones relacionadas con los modos de representación asociados a periodos históricos y culturas determinadas, o afrontando el tema de la relación entre el observador y la representación. Una descripción más detallada de estas diferentes tipologías puede encontrarse en el capítulo titulado, precisamente, "Metaimágenes", en W. J. T. Mitchell, op. cit., pp. 40-78.
} 
esto es, pueden condensar a nivel visual determinadas propuestas teóricas, o reflejar de algún modo cómo las ideas se desarrollan dentro de una línea de pensamiento determinada. Para aclarar qué quiere decir con esto, Mitchell platea algunos ejemplos como la "cámara oscura, la tabula rasa y la Caverna de Platón" que servirían para mostrar "la tendencia que tienen las tecnologías visuales a asumir un papel central en las representaciones del yo y de su conocimiento, de objetos, de otros y de sí mismo". Estos no serían "meros modelos epistemológicos, sino "conjuntos» éticos, políticos y estéticos" de manera que "en su forma más potente, no sirven como meras ilustraciones de la teoría, sino que dan imagen a la teoría" (p. 51). Un caso que Mitchell propone como especialmente esclarecedor ya que "proporciona una imagen de la forma de escribir de Foucault y de toda su teoría sobre la estratificación del conocimiento y de las relaciones de poder en la dialéctica de lo visible y lo decible" sería "su pequeño ensayo sobre Magritte y el hipericono de "Ceci n'est pas une pipe»" (p. 69).

Por lo que respecta al presente escrito, la intención como se ha dicho, con todas las reservas que cabría esperar de un trabajo de esta naturaleza, es similar. Por un lado las obras recogen a nivel formal esa idea de imágenes que sirven como reflexión sobre la propia imagen, imágenes que hablan acerca de imágenes. Por el otro, la intención final es que sirvan de "hipericonos", si se quiere parciales, a los planteamientos de los autores que se irán viendo, y que habrían de contribuir en última instancia a esa tarea propuesta de inquietar el ver.
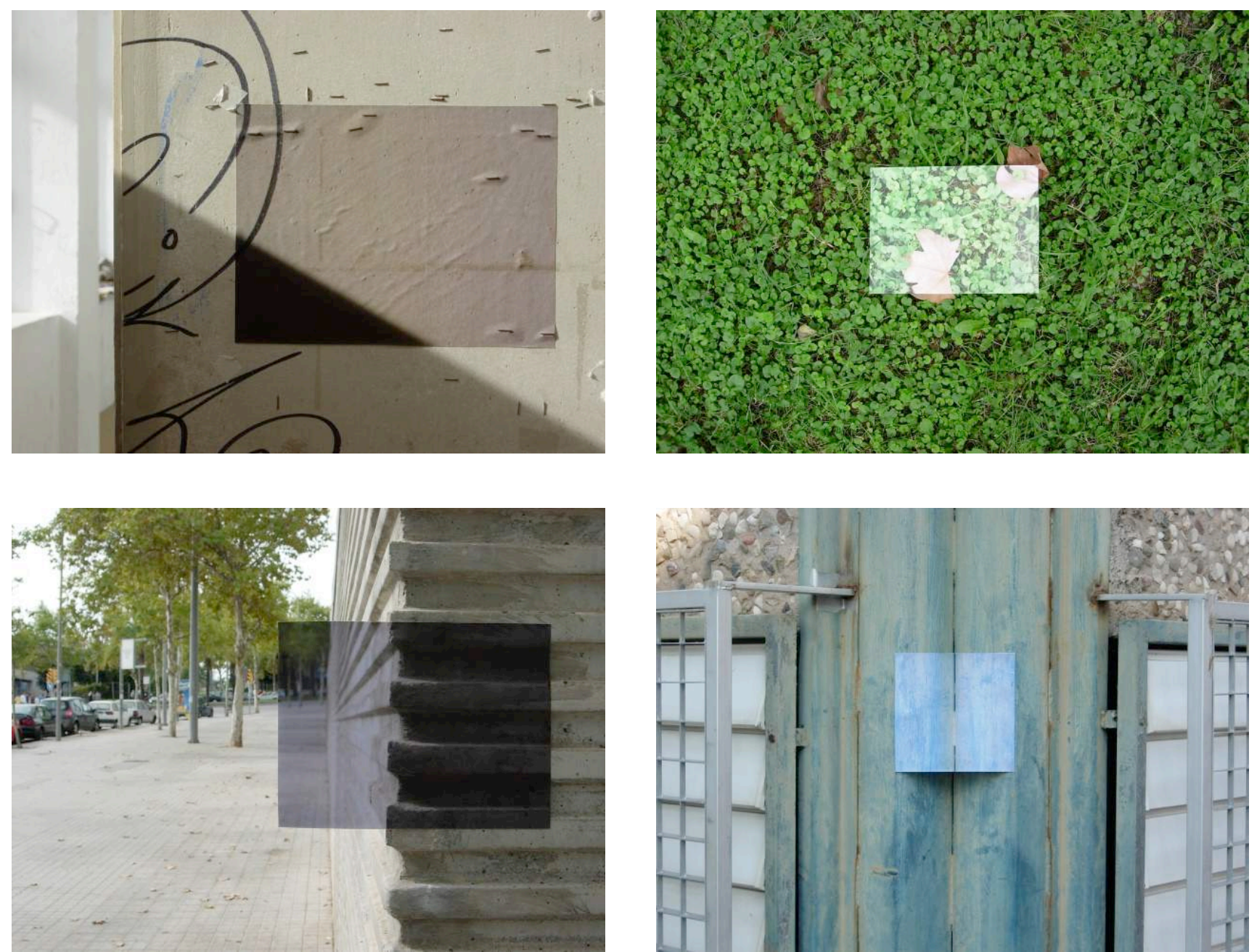

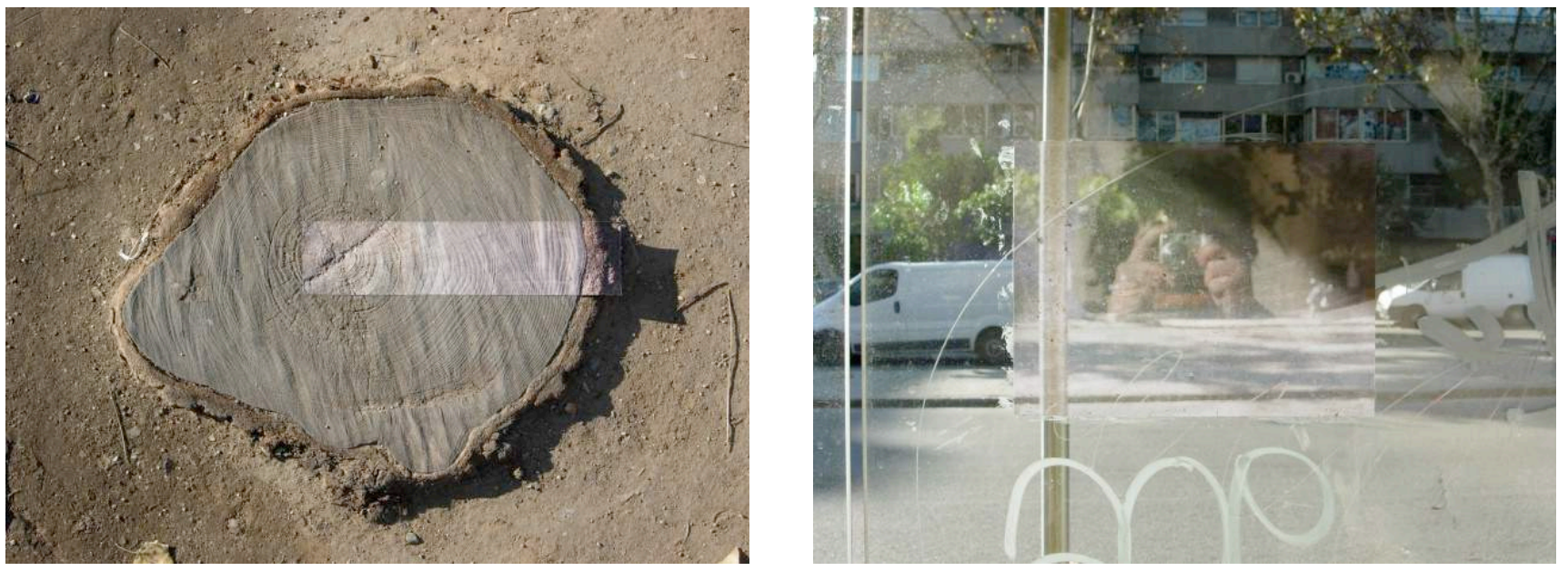

1. Déjà-vu, 2005

\section{RETÓRICA DE LA OCULTACIÓN}

Con la fórmula ocultar/visibilizar podría de algún modo verse recogido lo que desde la perspectiva de este trabajo ponen en funcionamiento las propuestas visuales pertenecientes a la línea de investigación. Dependiendo del ejemplo concreto en el que nos fijemos, ocultan, tapan, velan, arrebatan algo a la mirada, pero siempre de manera ambigua, sin llegar a hacerlo del todo, haciendo que emerja algo por debajo del obstáculo impuesto, ocultando y dando a ver en el mismo movimiento.

En varios de sus escritos, Miguel A. Hernández Navarro ha señalado como mecanismo recurrente en la práctica artística contemporánea algo que ha denominado el "procedimiento ceguera". Existen en la actualidad trabajos ante los que "la mirada se inquieta, y en el espectador se produce un profundo efecto de ceguera, de no saber a ciencia cierta qué está viendo, o más bien, qué no está viendo". ${ }^{4}$ Preguntándose sobre qué las anima, el autor reconoce en estas prácticas "un arte de resistencia, que se precipita contra la hegemonía hipervisual de la postmodernidad neoconservadora" (p. 6). Se trata en ellas por tanto "de inquietar un ver saturado [...]. Siniestralizar el ver para devolver la mirada, cegar para ver de nuevo" (p. 7). En conexión con esa noción desarrollada por Freud, en las "poéticas antivisuales" lo siniestro sería entonces

como una especie de déjà-vu que puede llegar a establecer una virtual conexión entre una "no-primera- vez" y una "primera-vez". Algo que acaso fue familiar y ha llegado a resultar extraño e inhóspito, y que precisamente por esa razón nos perturba y nos angustia, porque recuerda algo que debiendo permanecer oculto, ha salido a la luz. ${ }^{5}$

De entre las estrategias identificadas por Miguel A. Hernández-Navarro, el autor destaca una de ellas por evidenciar como ninguna otra el carácter crítico de este modo de trabajar. Es la denominada "retórica de la ocultación", un procedimiento que "elimina de la vista el asunto principal de la obra" y a la vez muestra un resto de lo ocultado, "una suerte de "punta de iceberg" de lo visible". ${ }^{6}$ Se trata de introducir una "disyunción que fractura la visión de totalidad y produce una escisión en el ver, una escisión, por decirlo en palabras de Didi-Huberman, entre lo que vemos y lo que nos mira, que es precisamente aquello que no podemos ver" (p. 7).

\footnotetext{
${ }^{4}$ Miguel Á. Hernández-Navarro, “(La) nada para ver”, Debats $n^{\circ}$ 82, Valencia, Otoño 2003, p. 2. En la praxis corresponderían a trabajos como los embalajes de Christo, las instalaciones del artista Británico Martin Creed, los monumentos invisibles del alemán Jochen Gerz, algunas obras de Land Art como las de Smithson o las siluetas de Ana Mendieta, por citar algunas.

${ }^{5}$ Miguel Á. Hernández-Navarro, "El arte contemporáneo entre la experiencia, lo antivisual y lo siniestro", Revista de Occidente, n 297, 2006, p.20.

${ }^{6}$ Miguel Á. Hernández-Navarro, Más allá del placer de la visión. Apuntes sobre "lo escondido" en el arte contemporáneo, Centro de $\begin{array}{llll}\text { Estudios Visuales Chile 2013-01-20]. } & \text { [consulta }\end{array}$
} «http://www.centroestudiosvisuales.net/centro/MiguelAngelHernandezNavarro_agosto2009.pdf), p.3-4. 


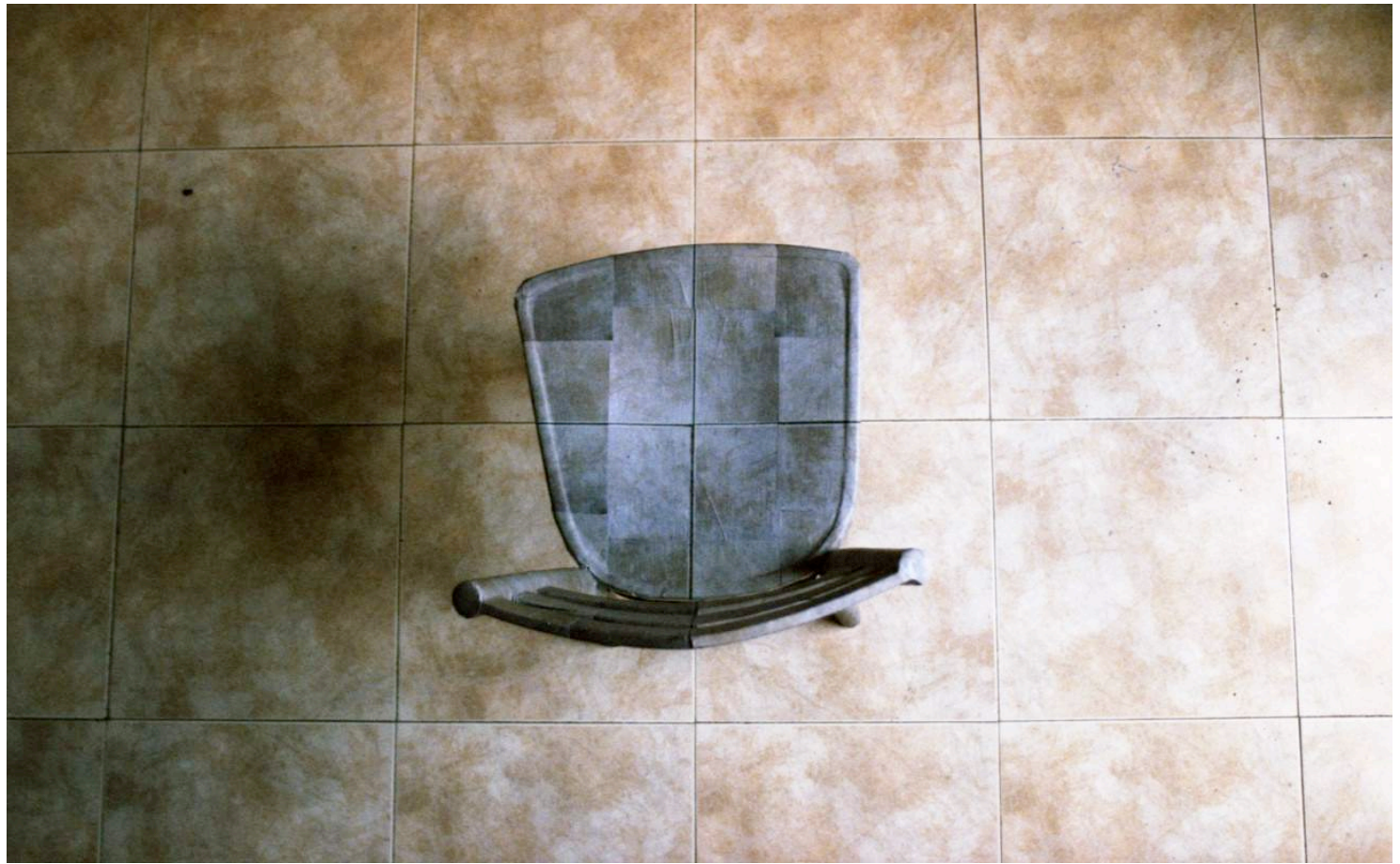

2. Silla; Proyecciones de Déjà-vu I, 2008

\section{IMAGEN DIALÉCTICA}

Es en esa escisión mencionada donde precisamente tomaría asiento una noción con la que en segundo lugar, pienso pueden identificarse los trabajos producidos: la de "imagen dialéctica". Tal y como la ha desarrollado Didi-Huberman -apoyándose entre otros en Benjamin-, ésta descansaría sobre lo que es el leitmotiv de su libro, la "ineluctable escisión del ver", la falla, la zona de emergencia entre "lo que vemos y lo que nos mira". " La imagen dialéctica vendría a instaurarse en la brecha no para ver un dilema en la oposición de pensamientos binarios, sino para poner en marcha un movimiento de oscilación en torno a un punto central de inquietud. Dialectizar las dimensiones de la imagen no para llegar a la síntesis transcendental (p. 45), sino para atender a la apertura en proceso, ya que entendido de esta forma -y conectando con Mitchell- "dar a ver es siempre inquietar el ver, en su acto, en su sujeto" (p. 47). A partir de aquí podemos pensar con Didi-Huberman, cómo en todo objeto se puede reconocer una "puesta en obra de lo figurable", esa "vocación esencial de toda superficie que nos mira, es decir de toda superficie que nos concierne más allá de su visibilidad evidente" (p. 56); en el sentido de que sólo se puede decir "Veo lo que veo si negamos a la imagen el poder de imponer su visualidad como una apertura, una pérdida [...] practicada en el espacio de nuestra certidumbre visible". En definitiva, y apuntando ahora a las obras de la línea de investigación "como si la invención de una imagen, por más simple que sea, correspondiera en primer lugar al acto de construir, fijar mentalmente un objeto-pregunta" (p. 69).
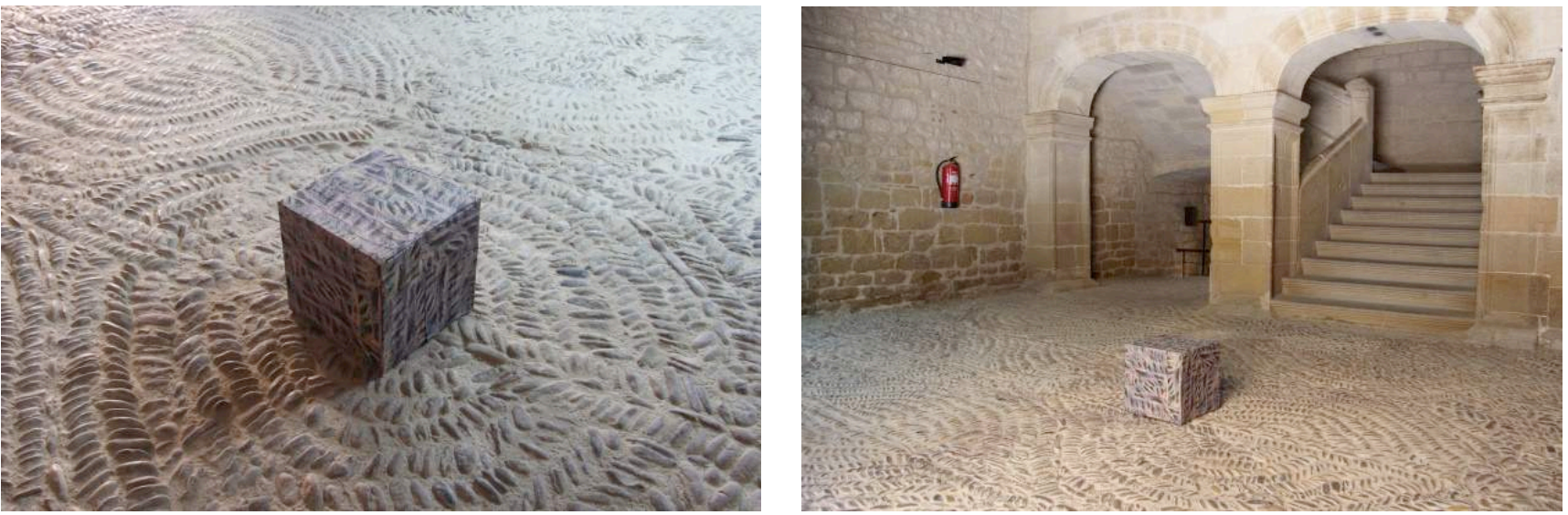

3. Stone-Box (proyecciones de Déjà-vu II), 2012 

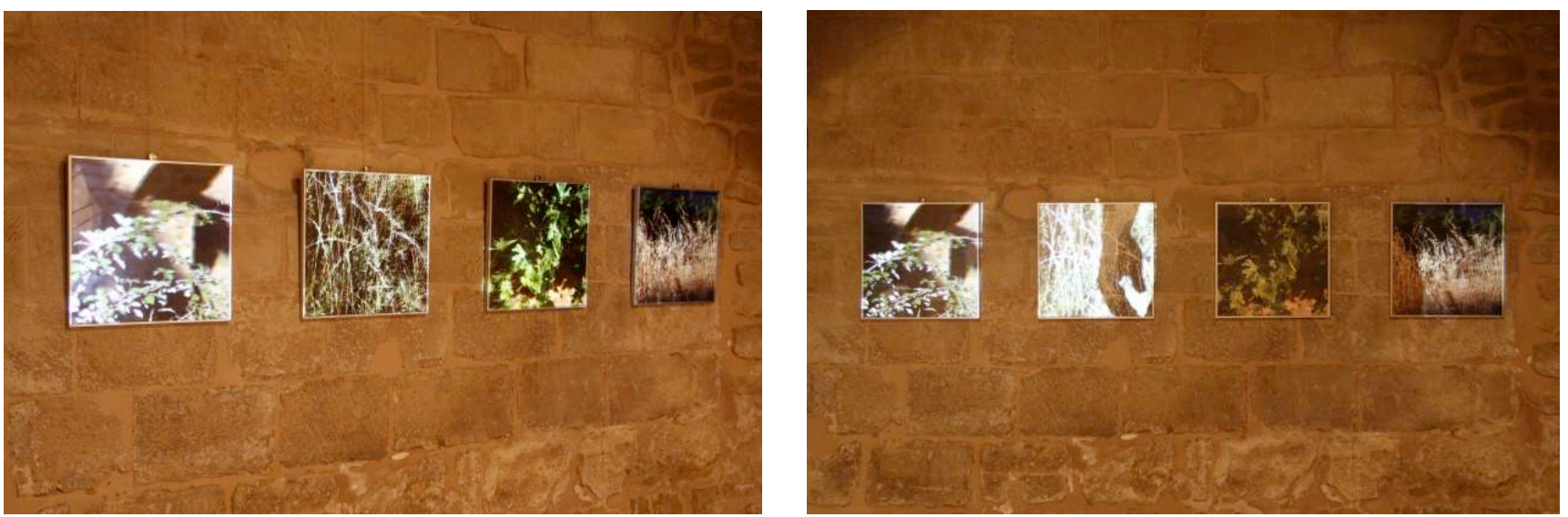

4. Atardecer en la vega del Riguel, 2012

\section{IMAGEN PENSATIVA}

Conectando ahora con el pensamiento de Jacques Rancière, podríamos asimilar aquello que surge de dialectizar la "aparente dicotomía" latente en la imagen con "esa tercera cosa de la que ninguno es propietario, de la que ninguno posee el sentido, que se erige entre los dos [artista y espectador], descartando toda transmisión de lo idéntico, toda identidad de causa y efecto" ${ }^{8}$ Esto estaría estrechamente relacionado con otra figura que propone el autor: el disenso. Así, en un escenario en el que éste estuviera presente obtendríamos "una organización de lo sensible en la que no hay ni realidad oculta bajo las apariencias, ni régimen único de presentación y de interpretación de lo dado que imponga a todos su evidencia" (p. 51). Con esto intenta desarticular algunas ideas arraigadas entorno a los medios de masas, a esas "máquinas de información", a las cuales se "acusa de ahogarnos con un mar de imágenes. Pero lo que hacen es todo lo contrario. No se contentan con reducir el número de imágenes que ponen a disposición. Ordenan antes que nada su puesta en escena". ${ }^{9}$ En contraste con esto, Rancière analiza un tipo de imagen particular y la actividad que la caracteriza, la "pensatividad". Ésta designaría en la imagen

algo que resiste al pensamiento, al pensamiento de aquel que la produjo y al de aquel que busca identificarla [...] no es una propiedad constitutiva de la naturaleza de ciertas imágenes, sino un juego de distancias entre varias funciones-imágenes presentadas sobre la misma superficie. ${ }^{10}$

Hablar de imagen pensativa es señalar entonces la existencia de una zona de indeterminación "entre pensado y no pensado, entre actividad y pasividad, pero también entre arte y no arte" (p. 105). Ésta supone "un cambio de estatuto de las relaciones entre pensamiento, arte, acción e imagen. Ese cambio marca el pasaje de un régimen representativo de la expresión a un régimen estético". ${ }^{11}$

\footnotetext{
${ }^{7}$ Didi-Huberman, G., Lo que vemos, lo que nos mira, Buenos Aires, Manantial, 1997.

${ }^{8}$ Rancière, J., El espectador emancipado, Buenos aires, Manantial, 2010, p.21.

${ }^{9}$ Rancière, J., "El teatro de las imágenes", en Didi-Huberman, G.; Jaar, A.; Pollock, G.; Rancière, J.; Schweizer, N., La Politica de las imágenes, Santiago de Chile, Metales Pesados, 2008, pp. 74-75. El tema del exceso de imágenes en la sociedad occidental tiene una historia que el autor se preocupa de desarticular, llegando a los orígenes de esa afirmación para ver a qué intereses responde realmente, pp. 72-75; y en El espectador emancipado, op.cit., pp. 49-51.

${ }_{10}$ Rancière, J., El espectador emancipado, op. cit., p. 126.

${ }^{11} \mathrm{Ibid}$., p. 117. Ese régimen vendría a ser la combinación indefinida y no cerrada de las dos grandes formas de operar de la imagen, el régimen moderno y el clásico (p. 118). La pensatividad sería entonces "la tensión entre varios modos de representación" (p. 112), "el producto de ese nuevo estatuto de la figura que conjuga, sin homogeneizarlos, dos regímenes de expresión" (p. 119), o de otra forma, "la presencia de un régimen de expresión dentro de otro" (p. 121).
} 

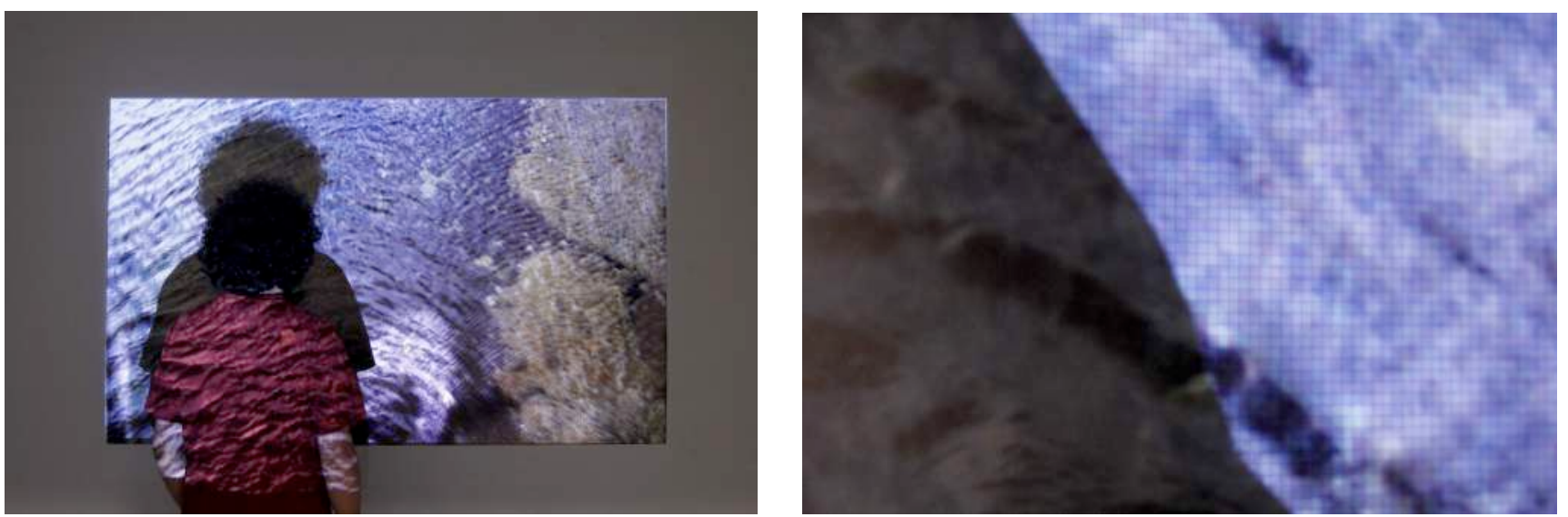

5. $S / T, 2013$

\section{HIPERVISIÓN ADMINISTRADA}

José Luis Brea, apoyándose en las investigaciones realizadas por Martin Jay, define "régimen escópico" o "episteme visual" como la "construcción social de un modelo general abstracto que articula como actividad cultural los actos de ver". ${ }^{12}$ Nuestro tiempo, tras la aparición de la imagen electrónica, inauguraría uno de "hipervisión administrada". En él, la noción de "inconsciente óptico" desarrollada por Benjamin- asociada a la era anterior, la de la imagen film, dará paso a la de "transparencia", y con ello las expectativas de saber sobre el ámbito del ver serán de nuevo modificadas. La idea moderna de que "no hay un conocimiento cumplido en el solo acto de ver, diríamos hasta que éste se completa con un trabajo de desciframiento, de lectura, que pondría luz a lo escondido en su punto ciego" (p. 58), va cediendo ante la idea que caracterizaría esta nueva episteme, la de que lo que está ahora en juego, lo que es "objeto de lucha" es el participar e intervenir activamente en la división y "redistribución de lo sensible", sujeta a determinadas "políticas del ver" con sus intereses particulares de dominación y hegemonía (p. 121). En este sentido Brea, en consonancia con el pensamiento de Rancière, plantea que no hay que oponer una resistencia frontal a las "potencialidades de transparencia de la tecnología" buscando crear zonas de "ceguera escópica", sino abogar por el empleo táctico de las tecnologías del ver para visibilizar aquello que se mantiene oculto (p. 122). Habla además de la existencia en este nuevo paradigma de un saber específico y propio de las imágenes, uno que consistiría en evidenciar cómo los "contenidos de conocimiento" son puestos en sus objetos y que "muestra que la puesta en obra de un efecto de cognición es resultado de un proceso de acrisolado público". Así, esa "potencia de cognición" de las imágenes, sería de "desmantelamiento", de denegación del conocimiento como algo ya dado, algo que en última instancia asocia a lo que Rancière denomina "régimen estético". En él, esa potencia de decir de la imagen sólo viene dada por su implicación en una episteme, y es tanto más capaz de movilizar una red de conexiones cuanto más se pone en "suspenso como objeto legible" (p. 128).
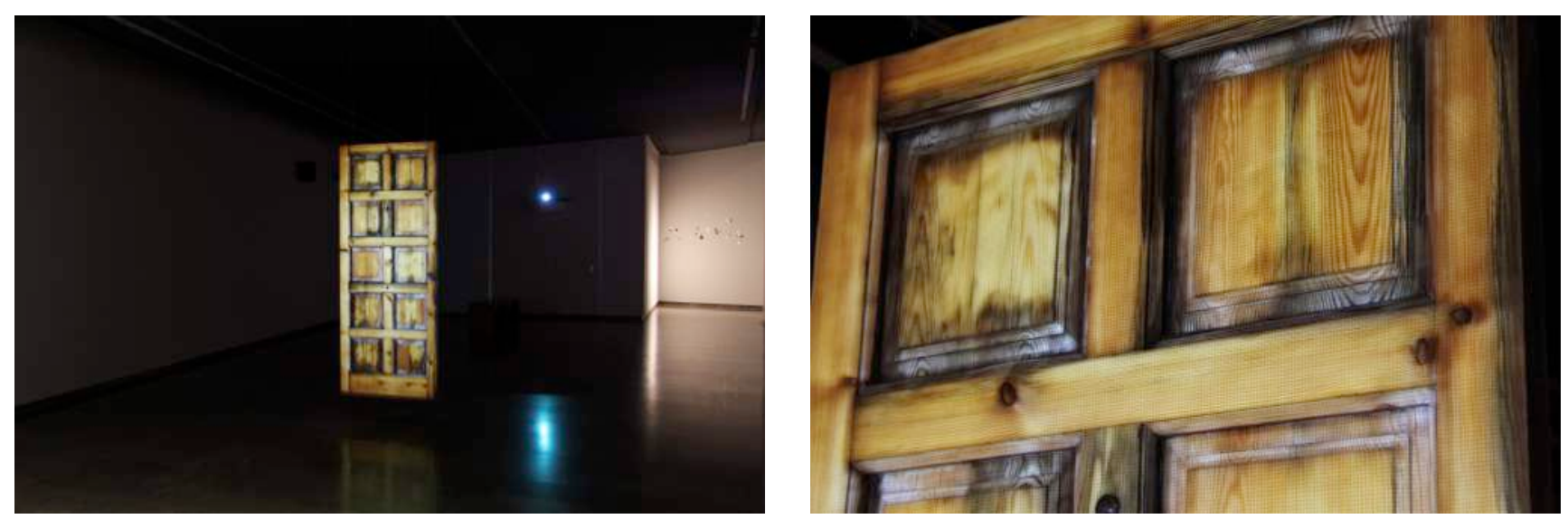

6. Puerta, 2014

\footnotetext{
${ }^{12}$ Brea, J. L., Las tres eras de la imagen. Imagen-materia, film, e-image, Madrid, Akal, 2010, p. 23.
} 


\section{LÓGICA PARADÓGICA DE LA IMAGEN}

Paul Virilio plantea que nuestro tiempo ha inaugurado una lógica paradójica asociada a la producción de imágenes, resultado de la aparición de lo digital, de lo virtual. En relación a ésta argumenta que aunque conocemos bien "la realidad de la lógica formal de la representación pictórica tradicional" y en menor medida "la actualidad de la lógica dialéctica" asociada a la representación "fotocinematográfica", no valoramos por el contrario más que muy torpemente "las virtualidades de esta lógica paradójica del videograma, del holograma o de la imaginería numérica", ${ }^{13}$ resumiéndola del siguiente modo:

La paradoja lógica es en definitiva la de esta imagen en tiempo real que domina la cosa representada [...]. Esta virtualidad que domina la actualidad, que trastorna la misma noción de realidad. De ahí esta crisis de las representaciones públicas tradicionales (gráficas, fotográficas, cinematográficas...) a favor de una presentación, de una presencia paradójica, telepresencia a distancia del objeto o del ser que suple su misma existencia aquí y ahora (p. 82).

De esta dinámica "resulta, en definitiva, «la alta definición», la alta resolución, ya no tanto de la imagen (fotográfica o televisual) como de la propia realidad" (pp. 82-83). Podemos ver a partir de aquí, cómo en varias de mis obras se materializa este pensamiento, pero a la vez bajo una forma de cortocircuito, de manera crítica, problematizando ese "a distancia", esa telepresencia de la imagen que en ellas se (im)pone sobre el propio objeto.
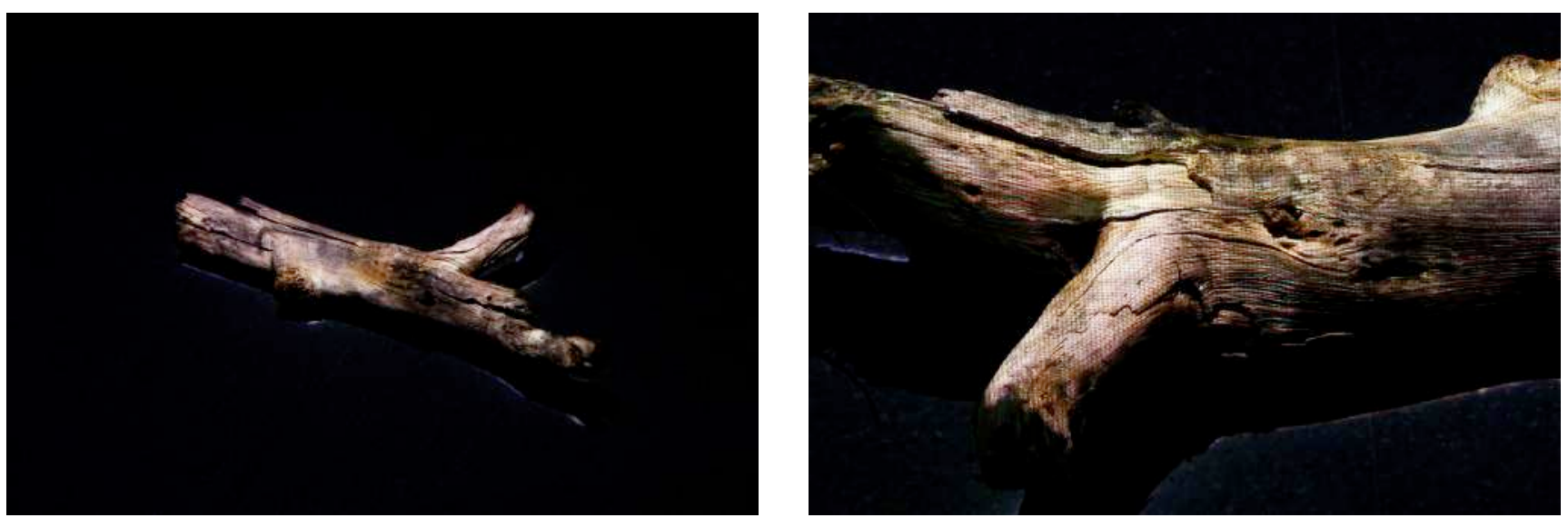

7. Tronco (automímesis), 2013

\section{REALIDAD INTEGRAL E IMAGEN RETORNANTE}

Llegamos así al último aspecto con el que podría relacionarse mi producción, planteado en este caso por Jean Baudrillard. Este autor habla de un tipo de violencia contemporánea, diferente de la mera agresión o la opresión, "la violencia de la información, de los medios de comunicación, de las imágenes, de lo espectacular. Violencias ligadas a la transparencia, a la visibilidad total". ${ }^{14}$ Esta violencia de la imagen y lo virtual consiste en que "todo debe ser visto, todo debe ser visible [...]. Todo lo real debe convertirse en imagen, aunque casi siempre a costa de su desaparición" (p. 48). Esa transparencia de la que habla Baudrillard -en claro contraste con el planteamiento de Brea-consistiría por lo tanto "en la proyección de todo lo real en la órbita de lo visual" (p. 54) donde "nada debe escapar al fundido-encadenado de la realidad y de la ficción" (p. 53).

La abolición de la distancia, la que se necesita "para que el mensaje se transmita, para que la imagen tenga eficacia sensible" (p. 66), hace que todo quede indeterminado, de manera que nos encontraríamos hoy en una situación de "realidad integral, sin distancia ni transcendencia" (p. 60). Ya no estaríamos hablando entonces de representación, sino de "una circunvalación de cosas que funcionan dentro de un bucle, que están abocadas a sí mismas [...] que chocan entre sí, se suturan y se saturan". Dicho de otro modo "realidad perfecta [...] en la que todo se identifica con el collage y con la confusión de su propia imagen". Así llegamos a lo que denomina una forma de implosión: "la imagen retornante [que] cortocircuita la mirada, cortocircuita la representación, duplicando la realidad por

\footnotetext{
${ }^{13}$ Virilio, P., La Máquina de visión, Madrid, Cátedra, 1998, p.82.

${ }^{14}$ Baudrillard, J., La agonía del poder, Madrid, Círculo de Bellas Artes, 2006, p. 46.
} 
adelantado e interceptando su desarrollo", un tipo de imagen "que en cierta medida clausura cada cosa enfocándola sobre sí misma, a través de una simulación automática de sí misma" (p. 63).
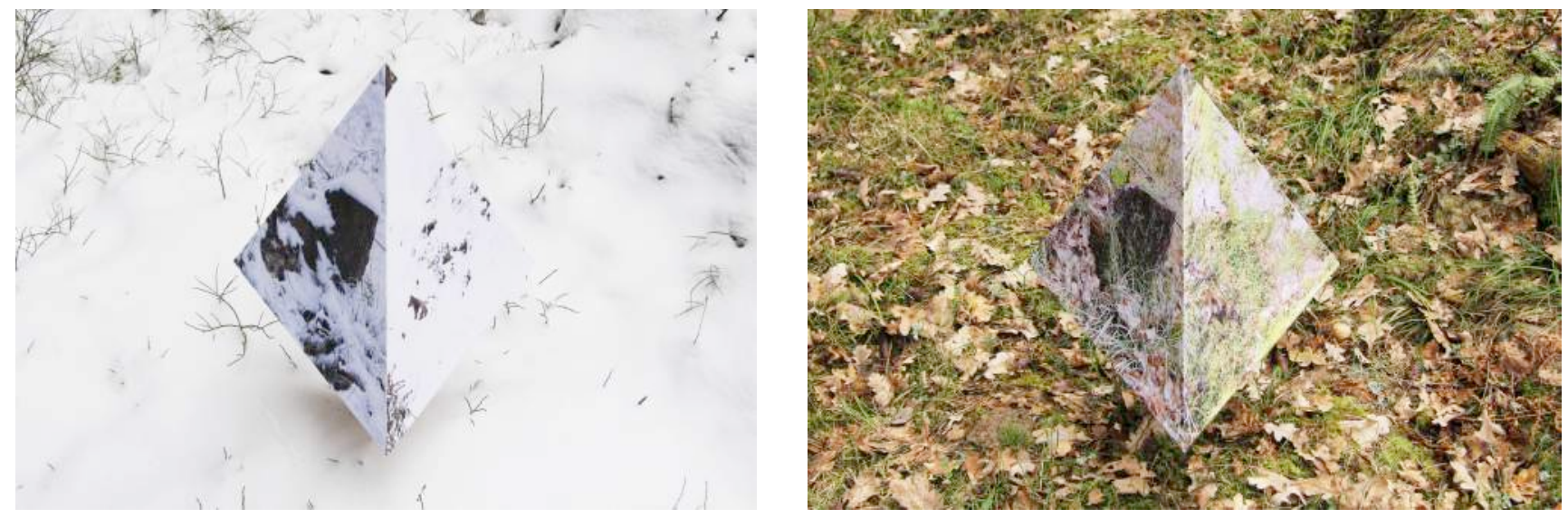

8. Saaren Tetraedri, 2014

\section{CONCLUSIONES}

¿De qué distancia se está hablando? ¿Cómo se puede interpretar esto en el marco del trabajo de investigación? En cierto sentido, tanto las obras ${ }^{15}$ como el trabajo en el que se han visto insertas pretenden, aunque de forma meramente tentativa, abordar tanto éstas como otras preguntas que han ido surgiendo en el proceso de investigación. Ese intento de inquietar el ver, de mostrarlo, abrirlo y en el mismo gesto extrañarlo, es lo que se ha intentado canalizar a lo largo de estas páginas. Algo importante es también, más allá de las afinidades vistas, ver que las obras permiten aglutinar autores cuyos planteamientos a veces no coinciden, o en ocasiones incluso se oponen, de manera que la imagen se inserta en un campo de tensiones en el que dialectizar posturas, para no dejar que el diálogo y la discusión cesen, sino que fruto precisamente del encuentro de esas ideas, que por su articulación en la imagen encuentran un punto de contacto que de otra manera tal vez no se habría advertido, apunten a nuevas conclusiones y abran nuevas vías de avance para el pensamiento. Finalmente, aunque las imágenes han sido incluidas coincidiendo con determinadas partes del texto, no quiere decir que únicamente condensen aquello que a nivel teórico se está tratando en ese momento. Así ciertos rasgos, ideas y potencialidades que surgirán a propósito del análisis de uno u otro autor podrán verse recogidas en mayor o menor medida dependiendo de la obra en que nos fijemos. En este sentido, y de acuerdo a lo visto, la idea no es vehicular un contenido de conocimiento cerrado sino generar un movimiento en el que el sentido surja de confrontar las ideas previas del lector-espectador, mis intenciones como investigador y artista visual y los materiales que conforman el presente trabajo visual-textual.

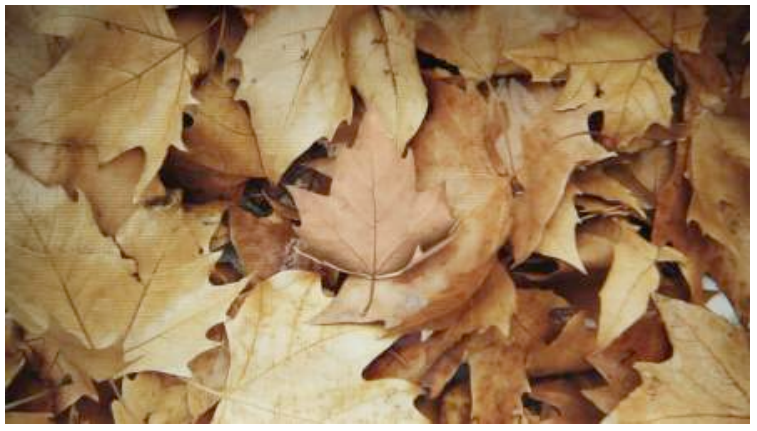

9. Fotograma del vídeo Hoja, 2013.

\footnotetext{
${ }^{15}$ Cabría hacer aquí un último inciso en relación a las obras. Cuando se habla de que el presente trabajo trata de vehicular la reflexión a través de la articulación entre ellas y los textos, se está pensado, de forma ideal, que con lo que se han puesto a dialogar los diferentes autores es con las obras propiamente dichas y no con las "imágenes" que como tal figuran en el texto. Esto, si bien para las piezas que en su formato original son fotografías no tiene tanta importancia, sí hay que tenerlo en cuenta para aquellas que son vídeos o instalaciones, ya que el modo de conectarlas en profundidad con lo aquí visto sería a partir de la experiencia de encontrarse ante ellas. Si bien esto es difícilmente solventable dadas las características del medio, pueden verse mejor documentadas a fin de hacerse una mejor idea de lo que plantean en mi blog: http://www.dacanto.blogspot.com.es/ y página web: http://www.davidcantarerotomas.com/. Igualmente, las obras aquí incluidas pertenecen todas a una misma línea de investigación, si bien las que han sido materializadas durante la realización del mencionado Máster corresponderían únicamente a las producidas a partir de 2013.
} 


\section{FUENTES REFERENCIALES}

Baudrillard, J., La agonía del poder, Madrid, Círculo de Bellas Artes, 2006.

Brea, J. L., Las tres eras de la imagen. Imagen-materia, film, e-image, Madrid, Akal, 2010.

- (ed.), Estudios Visuales. La epistemología de la visualidad en la era de la globalización, Madrid, Akal, 2005.

Mitchell, W. J. T., Teoría de la imagen. Ensayos sobre representación verbal y visual, Madrid, Akal, 2009.

—, "Mostrando el ver. Una crítica de la cultura visual”, Estudios Visuales, № 1, Madrid, Noviembre 2003.

Didi-Huberman, G., Cuando las imágenes tocan lo real, [consulta 2013-02-05]. Disponible en:

〈www.macba.es/uploads/20080408/Georges_Didi_Huberman_Cuando_las_imagenes_tocan_lo_real.pdf).

—, Lo que vemos, lo que nos mira, Buenos Aires, Manantial, 1997.

Didi-Huberman, G.; Jaar, A.; Pollock, G.; Rancière, J.; Schweizer, N., La Política de las imágenes, Santiago de Chile, Metales Pesados, 2008.

Foucault, M., Esto no es una pipa. Ensayo sobre Magritte, Barcelona, Anagrama, 1981.

Hernández-Navarro, M. Á., "Más allá del placer de la visión. Apuntes sobre «lo escondido» en el arte contemporáneo”, [versión] Espinosa. Revista de filosofía, VI, 8, Murcia, 2008. Centro de Estudios Visuales de Chile [consulta 2013-01-20]. Disponible en: 〈http://www.centroestudiosvisuales.net/centro/MiguelAngelHernandezNavarro_agosto2009.pdf〉.

_, “(La) nada para ver", Debats, no 82, Valencia, Otoño 2003 [consulta 2013-01-20]. Disponible en:

(www.alfonselmagnanim.com/debats/82/espais05.htm».

_, "El arte contemporáneo entre la experiencia, lo antivisual y lo siniestro", Revista de Occidente, no 297, Madrid, 2006.

Rancière, J., El espectador emancipado, Buenos aires, Manantial, 2010.

Virilio, P., La Máquina de visión, Madrid, Cátedra, 1998.

\section{ÍNDICE DE ILUSTRACIONES}

1. Déjà-vu, 2005, Fotografía a color (Realizadas a partir de intervención en el espacio público), 18×25cm (x6).

2. Silla; Proyecciones de Déjà-vu I, 2008. Fotografía a color (Realizada a partir de intervención en el espacio), 80×130cm.

3. Stone-Box (proyecciones de Déjà-vu II), 2012. Fotografía digital (díptico), (Realizadas a partir de intervención en el espacio), 50x70cm

4. Atardecer en la vega del Riguel, 2012. Instalación: fotografía digital, proyección, 50×50 (×4).

5. S/T, 2013. Instalación: fotografía a color, proyección, 105×170cm.

6. Puerta, 2014. Instalación: puerta, proyección doble, $202 \times 85 \times 5 \mathrm{~cm}$.

7. Tronco (automímesis), 2013. Instalación: tronco, proyección, 20×45×10cm.

8. Saaren Tetraedri, 2014. Multipágina (díptico), (Fotografías realizadas a partir de intervención en el espacio), 84,5×122cm c/u. (compuestas por 9 impresiones a color de $28,5 \times 41 \mathrm{~cm} \mathrm{c/u}$.)

9. Hoja (fotograma), 2013. Vídeo HD, Loop, 20". 